\title{
Virgaviridae: a new family of rod-shaped plant viruses
}

\author{
Michael J. Adams • John F. Antoniw • \\ Jan Kreuze
}

Received: 16 June 2009/Accepted: 26 August 2009/Published online: 28 October 2009

(C) Springer-Verlag 2009

\begin{abstract}
The new plant virus family Virgaviridae is described. The family is named because its members have rod-shaped virions (from the Latin virga $=$ rod), and it includes the genera Furovirus, Hordeivirus, Pecluvirus, Pomovirus, Tobamovirus and Tobravirus. The chief characteristics of members of the family are presented with phylogenetic analyses of selected genes to support the creation of the family. Species demarcation criteria within the genera are examined and discussed.
\end{abstract}

The International Committee on Taxonomy of Viruses (ICTV) has recently approved a proposal to create a plant virus family Virgaviridae. The family is named because its members have rod-shaped virions (from the Latin virga $=\operatorname{rod}$ ), and it includes the genera Furovirus, Hordeivirus, Pecluvirus, Pomovirus, Tobamovirus and Tobravirus. The chief characteristics of members of the family are:

1. Alpha-like replication proteins that form a distinct phylogenetic "family" [5].

2. Single-stranded RNA + sense genomes with a $3^{\prime}$-t-RNA-like structure and no polyA tail.

M. J. Adams $(\square)$. J. F. Antoniw

Department of Plant Pathology and Microbiology,

Rothamsted Research, Harpenden,

Hertfordshire AL5 2JQ, UK

e-mail: mike.adams@bbsrc.ac.uk

J. Kreuze

Germplasm Enhancement and Crop Improvement Division,

International Potato Center, Lima, 12, Peru
3. Rod-shaped virions $20-25 \mathrm{~nm}$ in diameter with a central "canal".

4. Coat proteins of $19-24 \mathrm{kDa}$.

It contains some viruses in which there is a single cellto-cell movement protein (MP) of the ' $30 \mathrm{~K}$ ' superfamily [7] and others that encode a triple gene block (TGB) [8]. There are also differences in the number of genomic RNAs (1, 2 or 3 depending on the genus), but sequence analysis of the polymerase and other genes suggests that the viruses form a coherent taxonomic unit (see below). Some properties of the six genera included in the family are summarized in Table 1, and their genome organization is shown in Fig. 1. Biologically, the viruses are fairly diverse. They have been reported from a wide range of herbaceous and mono- and dicotyledonous plant species, but the host range of individual members is usually limited. All members can be transmitted experimentally by mechanical inoculation, and for those in the genus Tobamovirus, this is the only known means of transmission. In some genera, transmission is by soil-borne vectors, while members of the genus Hordeivirus are transmitted through pollen and seed. The only genus with rod-shaped virions excluded from this list is Benyvirus, because this is much more distantly related in phylogenetic analyses of the polymerase (see below) and because (unlike the others) its members have a polyadenylated genome and a polymerase that is processed by autocatalytic protease activity.

On the basis of their analysis of the RNA-dependent RNA polymerase (RdRp) gene from a wide range of viruses, Koonin and Dolja [5] included viruses from the six genera described in this paper within RdRp Supergroup 3, which they sub-divided into three lineages that they suggested might correspond to orders. One of these lineages, which they named Tobamo, included the six genera 
Table 1 Major properties of the genera included in the new family Virgaviridae

\begin{tabular}{|c|c|c|c|c|c|c|}
\hline Genus & RNAs & $\mathrm{RdRP}^{\mathrm{a}}$ & $\mathrm{MP}^{\mathrm{b}}$ & $\mathrm{CP}^{\mathrm{c}}$ & $3^{\prime}$ Structure $^{\mathrm{d}}$ & Transmission \\
\hline Furovirus & 2 & RT & ' $30 \mathrm{~K}$ ' & $19 \mathrm{~K}+\mathrm{RT}$ & t-RNA ${ }^{\mathrm{Val}}$ & "Fungus" \\
\hline Hordeivirus & 3 & Separate & TGB & $22 \mathrm{~K}$ & $\mathrm{t}-\mathrm{RNA}^{\mathrm{Tyr}}$ & Seed \\
\hline Pecluvirus & 2 & RT & TGB & $23 \mathrm{~K}$ & t-RNA ${ }^{\text {Val }}$ & "Fungus" + seed \\
\hline Pomovirus & 3 & RT & TGB & $20 \mathrm{~K}+\mathrm{RT}$ & $\mathrm{t}-\mathrm{RNA} \mathrm{Val}^{\mathrm{Val}}$ & "Fungus" \\
\hline Tobamovirus & 1 & RT & ' $30 \mathrm{~K}$ ' & $17-18 \mathrm{~K}$ & t-RNA ${ }^{\mathrm{His}}$ & Mechanical \\
\hline Tobravirus & 2 & RT & ' $30 \mathrm{~K}$ ' & $22-24 \mathrm{~K}$ & t-RNA ${ }^{-}$ & Nematode \\
\hline
\end{tabular}

a Relation of RdRp to the replication protein (Methyltransferase, Helicase); RT, in a readthrough domain at the C-terminus

b MP movement protein either of the '30K' superfamily [7] or a Triple gene block (TGB [8])

c $\mathrm{CP}$ coat protein size (with indication of RT, a readthrough domain at the C-terminus if present)

d $\mathrm{t}_{\text {-RNA }} \mathrm{Val}^{\mathrm{T} / \mathrm{Tyr} / \mathrm{His} /-}, \mathrm{t}-\mathrm{RNA}$-like structure accepting valine, tyrosine, histidine or not aminoacylated, respectively

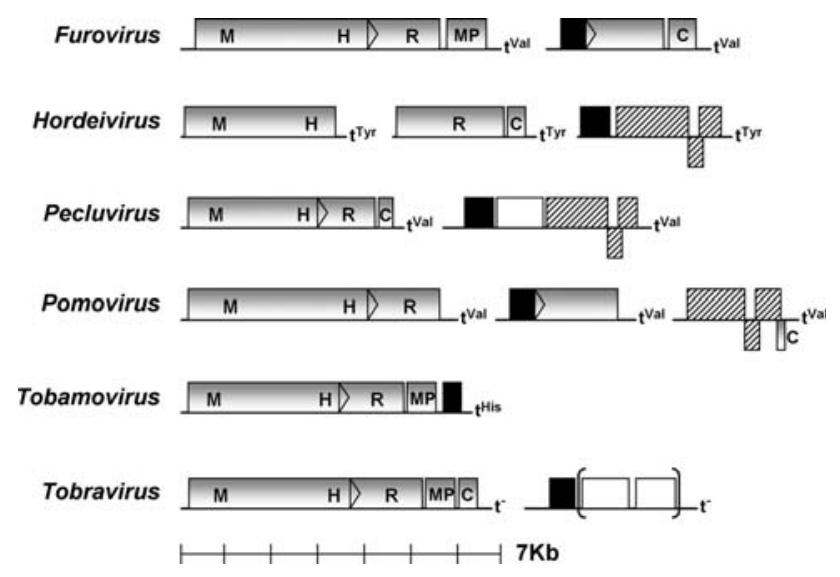

Fig. 1 Diagram showing the genome organization of the six genera included in the family Virgaviridae. Domains marked in the replication proteins are Methyltransferase $(\mathrm{M})$, Helicase $(\mathrm{H})$ and RNA-dependent RNA polymerase (R). Triple gene block proteins (TGB) are cross-hatched, and coat proteins are in black. MP, movement protein of the ' $30 \mathrm{~K}$ ' superfamily; $\mathrm{C}$, cysteine-rich protein. Positions of "leaky" stop codons are shown by triangles (filled triangles). $\mathrm{t}^{\mathrm{Val} / \mathrm{Tyr} / \mathrm{His} /-}$ : $\mathrm{t}$-RNA-like structure accepting valine, tyrosine, histidine or not aminoacylated, respectively. Brackets indicate ORFs that are missing from some strains

considered here, together with the families Closteroviridae and Bromoviridae and the genus Idaeovirus. Phylogenetic analysis (using several different methods) of the RdRp domain, of the whole replication protein or of the fused Methyl transferase-Helicase-RdRp domains continues to support this grouping and shows that the genus Benyvirus is much too distantly related to be grouped in this family (see Fig. 2). The inclusion within the branch of the families Closteroviridae and Bromoviridae also justifies the inclusion of all six genera within the single family Virgaviridae. The replication proteins constitute the majority of the genomes of these viruses and provide the best phylogenetic trees, but there are also indications of relatedness amongst the other genes. For example, the TGB proteins of the genera Hordeivirus, Pecluvirus and Pomovirus are clearly related and form a distinct group separate from those of the genus Benyvirus and the filamentous viruses in the family Flexiviridae (recently split into two families). A tree for TGBp1 sequences is provided in Fig. 3, and more details supporting this classification of the TGB proteins are provided by Morozov and Solovyev [8]. The small size of the coat protein and its inherent variability make it less suitable for phylogenetic analysis. Nevertheless, significant groupings of genera occur (Furo- with Pomo-; Peclu- with Hordei- and Tobra- a bit more distant) which correspond with those found within the RdRp (Fig. 4). There are also close relationships between the small cysteine-rich proteins of Furovirus, Hordeivirus, Pecluvirus and Tobravirus, although those of Pomovirus do not align well with them (data not shown).

The taxonomic structure of the new family and the species currently included are listed in Table 2.

Sequence differences between and within the existing species in the family were examined and compared with molecular criteria for species discrimination provided by the relevant study groups in the 8th ICTV report [2]. Individual pairwise comparisons were therefore made using the nt and aa sequences of each fully sequenced gene from every available accession in the family Virgaviridae contained in the international databases. Comparisons used the GCG [1] program GAP (with a gap creation penalty of 50 and a gap extension penalty of 3 for nt comparisons and values of 8 and 2 , respectively, for aa comparisons). This program aligns the two sequences selected and calculates the percentage identity and similarity between them. To assist with the large numbers of comparisons, software was written (Antoniw, unpublished) to generate batch files that were run in GCG and also to extract and summarize data from the output files. Some of the chief features of the data for the replication protein, the $\mathrm{RdRp}$ and the coat protein 


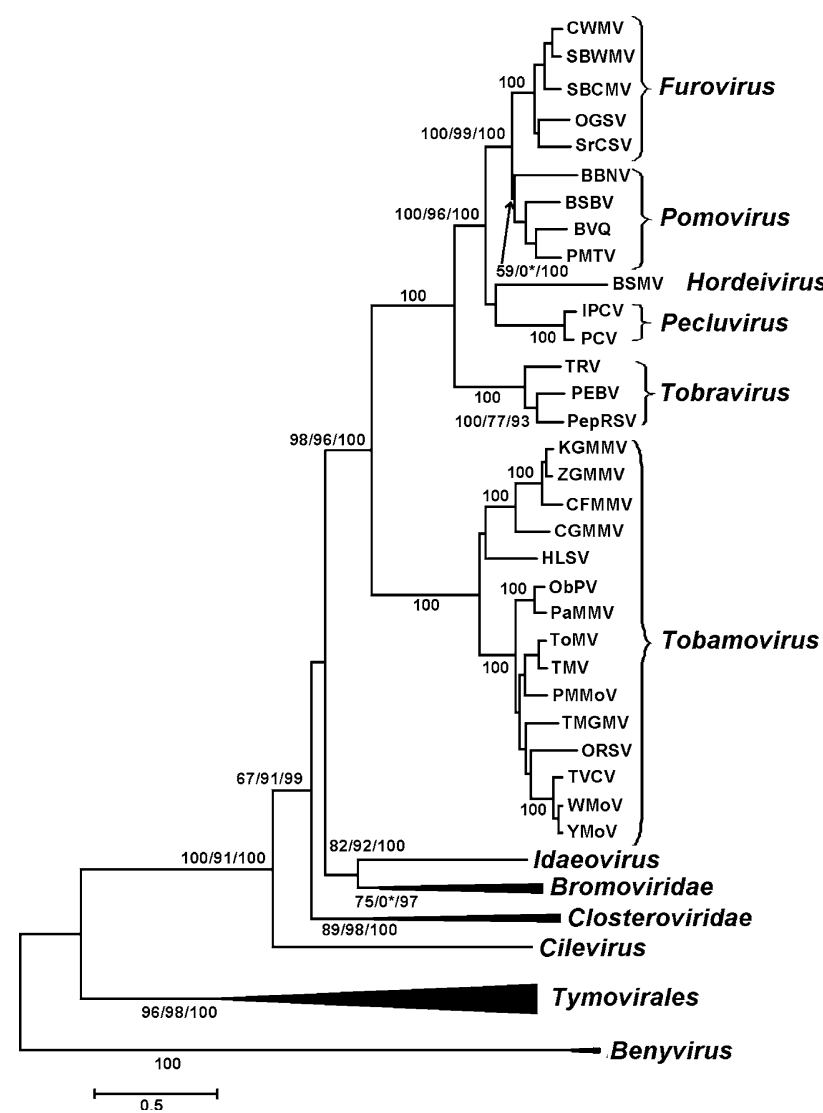

Fig. 2 Phylogenetic tree of the amino acid sequences of the fused Met-Hel-RdRp domains of the members of the six genera included in the family Virgaviridae together with some other related viruses. Distantly related genera and families that formed well-supported monophyletic clades were collapsed into a triangle, the length of which corresponds to the variation found within the clade. The recently established order Tymovirales includes the families Tymoviridae and Flexiviridae (which has also been divided). The neighbour-joining (NJ) tree is shown, but nearly identical trees were produced from the alignment using Maximum Composite Likelihood (ML) and Bayesian tree building algorithms. Percentage bootstrap support (out of 1,000 replications) for NJ and ML trees and posterior probability for the Bayesian tree are, respectively, indicated on the corresponding branches separated by slashes if they differed from each other. Values are only indicated on the major branches when $>60 \%$, and when values were identical, only one number is indicated (asterisk). The consensus tree generated by ML did not support the inclusion of BBNV into a Pomovirus clade and grouped the genus Idaeovirus within the Bromoviridae clade. The scale indicates JTT amino acid distances. Alignments were made from translated nucleotide sequences using the ClustalW algorithm in the Alignment Explorer module of MEGA4 [9] as described previously [6]. A total of 500 amino acid positions corresponding to 1,500 nt positions were used for the alignment. NJ and ML trees were generated using standard settings for these algorithms in MEGA4 [9] from protein and back-translated nucleotide alignments, respectively. The Bayesian tree was generated from back-translated nucleotide alignment using MrBayes v3.1.2 [4], employing the general time reversible model with gamma-shaped rate variation with a proportion of invariable sites; 1,000,000 generations of MCMC analysis were the point at which the average standard generation of split frequency between two parallel runs had reached 0.009565

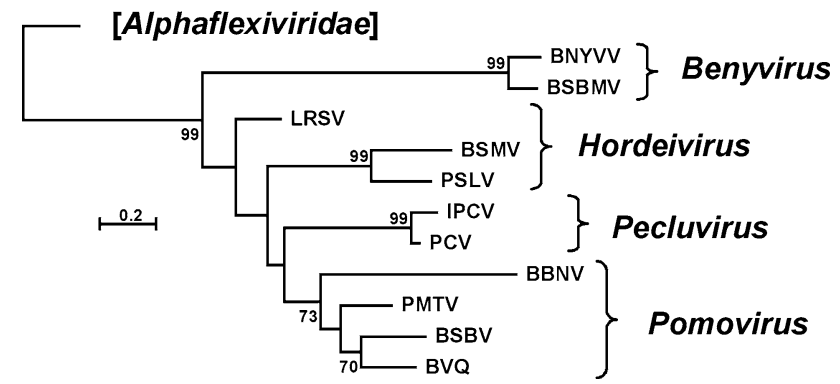

Fig. 3 Phylogenetic (neighbor-joining) tree of the amino acid sequences of the TGBp1 proteins of members of the genera included in the family Virgaviridae together with other TGB-containing viruses. Numbers on branches indicate percentage of bootstrap support out of 1,000 bootstrap replications (when $>60 \%$ ). The scale indicates JTT amino acid distances. Tree produced in MEGA4 [9]. A tree of similar typology was obtained by maximum-likelihood analysis (PROML in PHYLIP [3])

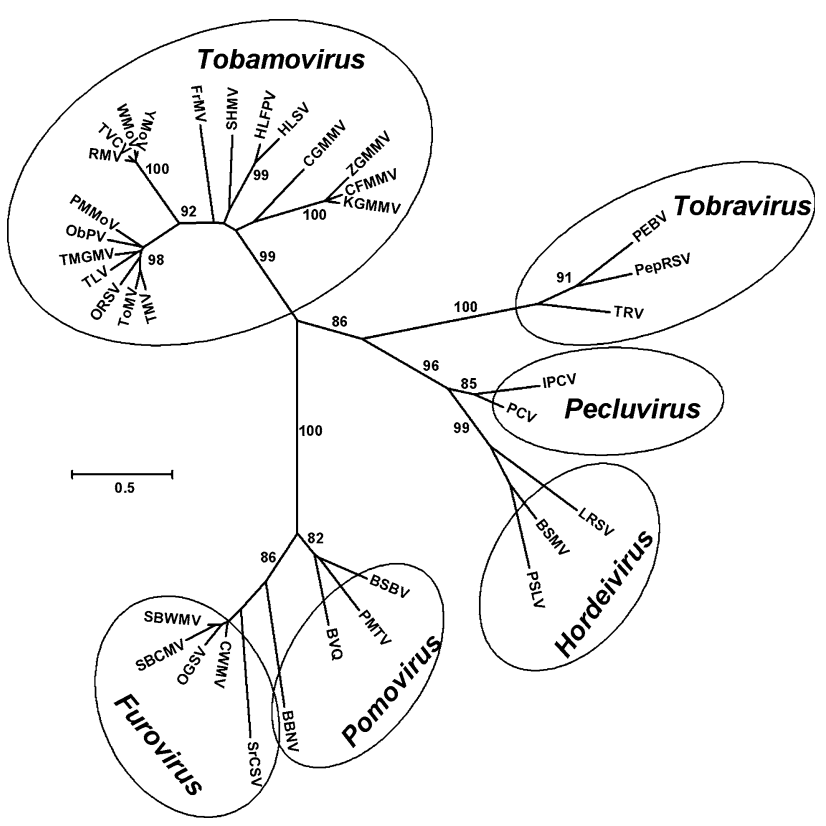

Fig. 4 Phylogenetic (neighbor-joining) tree of the amino acid sequences of the coat proteins of members of the genera included in the family Virgaviridae. Numbers on major branches indicate percentage of bootstrap support out of 1,000 bootstrap replications (when $>60 \%$ ). The scale indicates JTT amino acid distances. Tree produced in MEGA4 [9]. A tree of similar typology was obtained by maximum-likelihood analysis (PROML in PHYLIP [3])

genes are summarized in Table 3. Within some genera, there are rather few species and sequences, but some conclusions may nevertheless be reached. For the genus Tobravirus, it is already known that coat protein sequences (from RNA2) are of little taxonomic value [2], and this appears also to be the case for the genus Pecluvirus. Within the replication protein and RdRp, isolates of the same species usually had $>90 \%$ nt or aa sequence identity. Comparisons between genera show that some existing 
Table 2 List of species recognised within the genera belonging to the new family Virgaviridae with accession numbers for complete genome nucleotide sequences

\begin{tabular}{|c|c|c|}
\hline Species & Abbreviation & Isolate genome sequence(s) \\
\hline \multicolumn{3}{|l|}{ Genus Furovirus } \\
\hline Chinese wheat mosaic virus & CWMV & $\begin{array}{l}\text { AJ012005 + AJ012006 (NC_002359 + NC_002356); AJ271838 + AJ271839; } \\
\text { AB299271 + AB299272 }\end{array}$ \\
\hline Oat golden stripe virus & OGSV & $\mathrm{AJ} 132578$ + AJ132579 (NC_002358 + NC_002357) \\
\hline Soil-borne cereal mosaic virus & SBCMV & $\begin{array}{l}\text { AJ132576 + AJ132577 (NC_002351 + NC_002330); AF146278 + AF146282; } \\
\text { AJ252151 + AJ252152 }\end{array}$ \\
\hline Soil-borne wheat mosaic virus ${ }^{\mathrm{e}}$ & SBWMV & L07937 + L07938 (NC_002041 + NC_002042); AB033689 + AB033690a \\
\hline Sorghum chlorotic spot virus & SrCSV & $\mathrm{AB} 033691+\mathrm{AB} 033692$ (NC_004014 + NC_004015) \\
\hline \multicolumn{3}{|l|}{ Genus Hordeivirus } \\
\hline Anthoxanthum latent blanching virus & ALBV & No sequences available \\
\hline Barley stripe mosaic virus $^{\mathrm{e}}$ & BSMV & $\begin{array}{l}\text { J04342 + X03854 + M16576 (NC_003469 + NC_003481 + NC_003478); } \\
\text { U35768 + U35772 + U13918; U35766 + U35769 + U13916; } \\
\text { U35767 + U35770 + U13917; AY789693 + AY789694 + AY787207 }\end{array}$ \\
\hline Lychnis ringspot virus & LRSV & No complete genome sequences available \\
\hline Poa semilatent virus & PSLV & No complete genome sequences available \\
\hline \multicolumn{3}{|l|}{ Genus Pecluvirus } \\
\hline Indian peanut clump virus & IPCV & X99149 + AF447397 (NC_004729 + NC_004730) \\
\hline Peanut clump virus ${ }^{\mathrm{e}}$ & PCV & L07269 + Z97873 (NC_003668 + NC_003520) \\
\hline \multicolumn{3}{|l|}{ Genus Pomovirus } \\
\hline Beet soil-borne virus & BSBV & $\begin{array}{l}\text { Z97873 + U64512 + Z66493 (NC_003520 + NC_003518 + NC_003519); } \\
\text { EF545138 + EF545140 + EF545142; EF545139 + EF545141 + EF545143; } \\
\text { FJ971717 + FJ971718 + FJ971719 }\end{array}$ \\
\hline Beet virus $Q$ & BVQ & $\mathrm{AJ} 223596$ + AJ223597 + AJ223598 (NC_003510 + NC_003511 + NC_003512) \\
\hline Broad bean necrosis virus & BBNV & D86636 + D86637 + D86638 (NC_004423 + NC_004424 + NC_004425) \\
\hline Potato mop-top virus ${ }^{e}$ & PMTV & AJ238607 + AJ243719 + AJ277556 (NC_003723 + NC_003724 + NC_003725) \\
\hline \multicolumn{3}{|l|}{ Genus Tobamovirus } \\
\hline Brugmansia mild mottle virus & BruMMV & AM398436 (NC_010944) \\
\hline Cucumber fruit mottle mosaic virus & CFMMV & AF321057 (NC_002633) \\
\hline Cucumber green mottle mosaic virus & CGMMV & $\begin{array}{l}\text { D12505 (NC_001801); AB015146; AF417242; AF417243; EF611826; AB369274; } \\
\text { EU352259 }\end{array}$ \\
\hline Frangipani mosaic virus & FrMV & No complete genome sequences available \\
\hline Hibiscus latent Fort Pierce virus & HLFPV & $\begin{array}{l}\text { No complete sequence but FJ196834,AY596456 and AY250831 provide the coding } \\
\text { sequences] }\end{array}$ \\
\hline Hibiscus latent Singapore virus & HLSV & AF395898 (NC_008310) \\
\hline Kyuri green mottle mosaic virus & KGMMV & AJ295948 (NC_003610); AB015145; AB162006 \\
\hline Obuda pepper virus & $\mathrm{ObPV}$ & D13438 (NC_003852); L11665 \\
\hline Odontoglossum ringspot virus & ORSV & X82130 (NC_001728); U34586; U89894; S83257; AY571290; DQ139262 \\
\hline Paprika mild mottle virus & PaMMV & AB089381 (NC_004106) \\
\hline Pepper mild mottle virus & PMMoV & $\begin{array}{l}\text { M81413 (NC_003630); AB000709; AJ308228; AB069853; AY859497; AB126003; } \\
\text { AB113116; AB113117; AB254821; AB276030 }\end{array}$ \\
\hline Rehmannia mosaic virus & ReMV & EF375551 (NC_009041) \\
\hline Ribgrass mosaic virus & RMV & No complete genome sequences available \\
\hline Sammons's Opuntia virus & SOV & No sequences available \\
\hline Streptocarpus flower break virus & SFBV & AM040955 (NC_008365) \\
\hline Sunn-hemp mosaic virus & SHMV & An almost complete sequence is provided from a combination of U47034 and J02413 \\
\hline Tobacco latent virus & TLV & No complete genome sequences available \\
\hline Tobacco mild green mosaic virus & TMGMV & M34077 (NC_001556); AB078435; DQ821941; EF469769 \\
\hline Tobacco mosaic virus ${ }^{\mathrm{e}}$ & TMV & $\begin{array}{l}\text { V01408 (NC_001367); V01409; X68110; AF165190; AJ011933; D63809; AF273221; } \\
\text { AF395127; AF395128; AF395129; AB369275; AB369276 }\end{array}$ \\
\hline Tomato mosaic virus & ToMV & $\begin{array}{l}\text { AF332868 (NC_002692); AF155507; AJ243571; Z92909; X02144; AJ132845; } \\
\text { AJ417701; AB083196; DQ873692 }\end{array}$ \\
\hline Turnip vein-clearing virus & TVCV & U03387 (NC_001873); Z29370 \\
\hline
\end{tabular}


Table 2 continued

\begin{tabular}{|c|c|c|}
\hline Species & Abbreviation & Isolate genome sequence(s) \\
\hline Ullucus mild mottle virus & UMMV & No sequences available \\
\hline Wasabi mottle virus & WMoV & AB017503 (NC_003355) $)^{\mathrm{c}}$; AB017504 \\
\hline Youcai mosaic virus & YMoV & $\begin{array}{l}\text { U30944 (NC_004422); AF254924 (NC_002792) }{ }^{\text {d }} \text {; D38444; AY318866; DQ223770; } \\
\text { AB261175; EU571218 }\end{array}$ \\
\hline Zucchini green mottle mosaic virus & ZGMMV & AJ295949 (NC_003878); AJ252189 \\
\hline \multicolumn{3}{|l|}{ Genus Tobravirus } \\
\hline Pea early browning virus & PEBV & X14006 + X51828 (NC_002036 + NC_001368) \\
\hline Pepper ringspot virus & PepRSV & L23972 + X03241 (NC_003669 + NC_003670) \\
\hline Tobacco rattle virus ${ }^{\mathrm{e}}$ & TRV & AF166084 + Z36974 (NC_003805 + NC_003811); AF034622 + AF034621 \\
\hline
\end{tabular}

a Probably a different species

b There are sequences annotated as Ribgrass mosaic virus, but the definition of this species appears uncertain

c Annotated as crucifer tobamovirus wasabi strain

d Annotated as Ribgrass mosaic virus but seems to belong here while the definition of RMV appears uncertain

e Denotes type species

Table 3 Values from pairwise sequence comparisons for three genome regions amongst viruses in the family Virgaviridae

\begin{tabular}{|c|c|c|c|c|c|c|}
\hline & \multicolumn{2}{|c|}{ Most distantly related isolates of same species } & \multicolumn{2}{|c|}{ Most closely related species } & \multicolumn{2}{|c|}{ Most distantly related species } \\
\hline & aa & nt & aa & $\mathrm{nt}$ & aa & $\mathrm{nt}$ \\
\hline \multicolumn{7}{|c|}{ Replication protein } \\
\hline Furovirus & 95.1 & 94.3 & 82.5 & 72.7 & 52.7 & 56.5 \\
\hline Hordeivirus & 96.5 & 94.7 & NA & NA & NA & NA \\
\hline Pecluvirus & NA & NA & 88.6 & 78.0 & 88.6 & 78.0 \\
\hline Pomovirus & 99.7 & 99.6 & 54.9 & 59.2 & 45.3 & 54.9 \\
\hline Tobamovirus & 94.4 & 86.8 & 93.8 & 83.6 & 39.3 & 49.4 \\
\hline Tobravirus & 98.8 & 99.2 & 63.6 & 63.0 & 52.9 & 57.8 \\
\hline \multicolumn{7}{|l|}{$\mathrm{RdRp}$} \\
\hline Furovirus & 96.7 & 95.9 & 90.4 & 78.9 & 72.4 & 68.0 \\
\hline Hordeivirus & 98.1 & 98.4 & NA & NA & NA & NA \\
\hline Pecluvirus & NA & NA & 95.1 & 79.4 & 95.1 & 79.4 \\
\hline Pomovirus & 99.2 & 99.4 & 76.6 & 70.3 & 65.0 & 64.2 \\
\hline Tobamovirus & 95.4 & 87.2 & 96.2 & 86.0 & 52.8 & 57.1 \\
\hline Tobravirus & 99.2 & 99.0 & 79.8 & 71.6 & 75.5 & 68.7 \\
\hline \multicolumn{7}{|l|}{ Coat protein } \\
\hline Furovirus & 92.0 & 86.2 & 95.5 & 94.2 & 43.2 & 49.1 \\
\hline Hordeivirus & 98.0 & 97.7 & 55.6 & 60.1 & 40.8 & 48.1 \\
\hline Pecluvirus & 40.6 & 50.1 & 66.5 & 64.8 & 36.5 & 45.8 \\
\hline Pomovirus & 97.7 & 98.7 & 53.0 & 58.8 & 29.1 & 42.4 \\
\hline Tobamovirus & 87.7 & 88.5 & 93.0 & 90.9 & 26.7 & 38.9 \\
\hline Tobravirus & 38.6 & 45.2 & 89.2 & 77.5 & 36.2 & 48.6 \\
\hline
\end{tabular}

Amino acid (aa) and nucleotide (nt) identities are provided for each genus, showing the most distantly related isolates of the same species and the minimum and maximum values for comparisons between different species. Criteria for species discrimination listed in the in 8th ICTV report [2] are also shown

Furovirus: less than about 75 or $80 \%$ nt identity on RNAs 1 and 2, respectively

Hordeivirus: no criteria provided

Pecluvirus: no molecular criteria provided

Pomovirus: less than about $80 \%$ identical over the whole sequence; less than about $90 \%$ identical in $\mathrm{CP}$ amino acid sequence

Tobamovirus: less than $10 \%$ overall nt sequence difference is considered to characterize strains of the same species

Tobravirus: nucleotide sequences of RNA-1 show $<75 \%$ identity; RNA-2 sequences are of limited value 
species in the genus Tobamovirus are rather closely related and there may be merit in re-examining the species demarcation criteria within this genus.

Acknowledgments Rothamsted Research receives grant-aided support from the Biotechnology and Biological Sciences Research Council of the UK.

\section{References}

1. Anon (2001) Wisconsin package version 10.3. Accelrys Inc., San Diego, CA

2. Fauquet CM, Mayo MA, Maniloff J, Desselberger U, Ball LA (2005) Virus taxonomy: eighth report of the International Committee on Taxonomy of Viruses. Elsevier Academic Press, San Diego
3. Felsenstein J (1993) PHYLIP (phylogeny inference package) version 3.6. Distributed by the author. Department of Genetics, University of Washington, Seattle

4. Huelsenbeck JP, Ronquist F (2001) MRBAYES: Bayesian inference of phylogeny. Bioinformatics 17:754-755

5. Koonin EV, Dolja VV (1993) Evolution and taxonomy of positivestrand RNA viruses: implication of comparative analysis of amino acid sequences. Crit Rev Biochem Mol Biol 28:375-430

6. Martelli GP, Adams MJ, Kreuze JF, Doja VV (2007) Family Flexiviridae: a case study in virion and genome plasticity. Annu Rev Phytopathol 45:73-100

7. Melcher U (2000) The ' $30 \mathrm{~K}$ ' superfamily of viral movement proteins. J Gen Virol 81:257-266

8. Morozov SY, Solovyev AG (2003) Triple gene block: modular design of a multifunctional machine for plant virus movement. J Gen Virol 84:1351-1366

9. Tamura K, Dudley J, Nei M, Kumar S (2007) MEGA4: molecular evolutionary genetics analysis (MEGA) software version 4.0. Mol Biol Evol 24:1596-1599 